Віктор Свгенович Бобильов (канд. військ. наук, с.н.с.)

Роман Родіонович Тимоченко (канд. техн. наук)

Національний університет оборони Украӥни імені Івана Черняховського, Київ, Украӥна

\title{
ПІДХІД ДО АНАЛІЗУ ДАНИХ У ЗАСОБАХ ІМІТАЦІЙНОГО МОДЕЛЮВАННЯ БОЙОВИХ ДІЙ ВІЙСЬК (СИЛ)
}

\begin{abstract}
У статті розглядається один з можливих методичних підходів до побудови засобів імітаційного моделювання бойових дій тактичного рівня для тактичних підрозділів сухопутних військ. Уводиться поняття типового об'єкта для ведення бою, бойової одинииі, яка не підлягає поділу на більщ дрібні складові і здатна самостійно виконувати у ході ведення бойових дій наступні завдання: здійсненя маневру; ведення розвідки противника; ведення вогню по противнику, а також приймати рімення на виконання зазначених вище завдань. Подібні засоби імітаџійного моделювання можуть лягти в основу засобів імітаційного моделювання більш високих рівнів управління, в яких основна увага приділяється процесу прийняття рімення. Виконано формалізацію иього процесу. Запропоновано підхід до аналізу та обробки даних, на основі яких приймаються рімення з управління типовим бойовим об'єктом (підрозділом).
\end{abstract}

Ключові слова: імітаційне моделювання, модель управління, прийняття рімень за допомогою засобів імітаційного моделювання.

\section{Ветуп}

Ефективності ведення бойових дій завжди приділялася особлива увага. Протягом багатьох століть знання і вміле керівництво підлеглими 3 боку відповідних військових командувачів (командирів) у ході ведення бойових дій (операцій) дозволяли зберігати життя не тільки підлеглих військовослужбовців, але i, у цілому, значної кількості звичайних людей. $\mathrm{y}$ ході бойових дій часто вирішувалася доля цілих держав. Досвід, здобутий у попередніх боях, передавався з покоління у покоління та постійно вдосконалювався у ході ведення реальних бойових дій, але ціною людських життів, що підтверджується досвідом ведення бойових дій у зоні операції об'єднаних сил на сході України.

Постановка проблеми. У сучасних умовах для підготовки майбутніх командирів, а також аналізу та прогнозування ходу та результату ведення бойових дій різного масштабу широко застосовується моделювання і особливо імітаційне. Використання засобів імітаційного моделювання дозволяс 3 меншими витратами матеріальних та фінансових ресурсів, відсутністю втрат в особовому складі та військовій техніці і озброєнні вирішити поставлене завдання та прийняти обгрунтоване i ефективне рішення в умовах тієї чи іншої штучно створеної оперативнотактичної обстановки.

При моделюванні бойових дій найбільшого поширення набуло імітаційне моделювання зважаючи на складність моделювання військових дій, як таких, у цілому. Як правило, у бойових діях бере участь велика кількість об'єктів, створення математичних моделей яких може бути дуже складним. Імітаційні ж моделі дозволяють вивчити ситуацію, що складається у ході ведення бойових дій та має для нас інтерес, 3 необхідним ступенем деталізації, 3 використанням різних принципів формування модельного часу. А багаторазове програвання виконання певного бойового завдання дозволить поповнити дані, яких нам бракує. Таким чином здійснюється перехід від ведення реальних боїв на поле бою до їх розіграшу за допомогою комп'ютерних програм імітаційного моделювання.

Аналіз остатніх досліджень і публікацій.

Приступаючи до розробки математичних моделей, необхідно визначитися 3 основними принципами їх створення, які дозволяють досягти запропонованих вимог до моделей, що розробляються $[1,2,3,5]$. До них відносяться:

1. Принцип декомпозиції системи, яка моделюється, на підсистеми. Принцип декомпозиції передбачає виділення підсистем, які, у свою чергу, можуть ділитися на більш дрібні елементи і т.д. Такий підхід дозволить створити математичну модель процесу ведення бойових дій, яка буде спиратися на алгоритми моделювання окремих об'єктів та алгоритми їх функціональної взаємодії у ході бою.

2. Принцип раціонального компромісу між рівнем деталізації моделей та складністю їх комплексу. Пошук раціонального компромісу пов'язаний 3 аналізом допустимих спрощень як вихідних алгоритмів функціонування окремих елементів, так і алгоритмів їх взаємодії. Критерієм такого компромісу $є$ ступінь досягнення цілей у результаті моделювання. При цьому у комплексі моделей повинна бути передбачена можливість урахування додаткових спрощень i, навпаки, можливість більшої деталізації опису деяких підсистем та їх елементів. 
3. Побудова комплексу моделей у вигляді ієрархічної агрегативної системи.

Процеси перетворення вхідної інформації у таких системах здійснюються 3 урахуванням поточного стану кожного агрегату. Формування вихідних сигналів відбувається відповідно до заданого алгоритму, який враховує особливості функціонування кожного агрегату та реально існуючі взаємозв'язки між ними.

Метою статті $\epsilon$ розгляд шляхів реалізації вище зазначених принципів та відповідний їм аналіз даних у засобах імітаційного моделювання бойових дій військ (сил).

\section{Виклад основного матеріалу дослідження.}

За основу візьмемо систему військового управління тактичного рівня, природно ієрархічну (відділення-рота) сухопутних військ (CB). Необхідно ввести поняття типового бойового об'єкта, під яким будемо розуміти вогневу одиницю, яка не може бути розбита на більш дрібні елементи, яка здатна самостійно виконувати у бою чотири основні завдання: маневрування (переміщення) на місцевості; ведення розвідки (спостереження) противника; нанесення противнику вогневого ураження (ураження цілей) та прийняття рішень на ведення бойових дій 3 урахуванням виконання зазначених вище завдань в умовах оперативно-тактичної обстановки, яка постійно змінюється (управління бойовим об'єктом). За типовий бойовий об'єкт приймемо механізоване (мотострілкове) відділення $\mathrm{CB}$, яке входить до складу механізованого (мотострілецького) взводу, який, у свою чергу, входить до складу механізованої (мотострілецької) роти СВ.

У такій ситуації математична модель типового бойового об'єкта повинна імітувати чотири основні функції: прийняття рішень (управління бойовим об'єктом); здійснення маневру (переміщення); ведення розвідки; вогневе ураження противника.

Відповідно до цього можна визначити підмодели, які будуть імітувати відповідні процеси, та будуть складовими загальної моделі ведення бойових дій. У такому разі структура моделі типового бойового об'єкта (див. Принцип 1) буде мати вигляд, що показаний на малюнку 1.

\begin{tabular}{|c|c|c|}
\hline \multicolumn{3}{|c|}{ Модель процесу управліния бойовим } \\
об’єктом \\
\hline $\begin{array}{c}\text { Модель } \\
\text { здійснення } \\
\text { маневру }\end{array}$ & $\begin{array}{l}\text { Модель } \\
\text { ведення } \\
\text { развідки }\end{array}$ & $\begin{array}{c}\text { Модель } \\
\text { вогневого } \\
\text { ураження }\end{array}$ \\
\hline
\end{tabular}

Малюнок 1. Структура моделі типового бойового об'єкта

Модель управління бойовим об'єктом повинна забезпечити реалізацію управлінських функцій командира - функцій прийняття рішень на всіх виділених вище етапах: здійснення маневру, ведення розвідки та вогневого ураження противника, а також функції внесення змін до раніше прийнятого рішення.

Процес здійснення маневру $\epsilon$ переміщення об'єктів у напрямках, які визначені поставленими бойовими завданнями, та зі швидкостями, що дозволяють здійснювати переміщення відповідно до рельєфу місцевості, часу доби, погодних умов та характеру дій, які реалізуються для вирішення поставленого завдання. При цьому на основі цифрової карти місцевості (ЦКМ) на кожен момент модельного часу потрібно оцінювати розташування бойового об'єкта (розраховувати поточні координати), який моделюється, та визначати параметри його руху.

Моделювання процесу ведення розвідки противника полягає в отриманні ряду показників, які характеризують можливість виявлення об'єктів противника в умовах оперативно-тактичної обстановки, що склалися під час іiі моделювання. На підставі цих показників приймається рішення про виявлення та розпізнавання об'єктів противника (цілей для вогневого ураження).

Модель вогневого ураження цілі включає:

визначення ймовірності влучення $\mathrm{y}$ ціль обраниою зброєю та визначення ймовірності піi поразки виходячи 3 тактико-технічних характеристик засобів вогневого ураження, характеристик цілі та умов оперативно-тактичної обстановки, що моделюється;

визначення збитку, який наноситься об'єктам противника при застосуванні по ньому певних засобів вогневого ураження.

Підхід до формалізації процесів здійснення маневру, ведення розвідки і вогневого ураження цілі 3 використанням цифрової карти місцевості для підрозділів сухопутних військ широко відомий [2]. Проте поведінка об'єктів, які моделюються, у цьому випадку задається виключно користувачем моделі та при цьому не враховується багатоваріантність розвитку подій у ході ведення бойових дій. Ця багатоваріантність обумовлена тим, що у будь-який момент часу можуть мати місце зміни оперативно-тактичної обстановки, які вимагають внесення змін до рішення на виконання раніше поставленого бойового завдання. Наприклад, в процесі моделювання при виникненні необхідності вибору маршруту здійснення маршу (маневрування) від деякого вихідного пункту у пункт призначення повинні бути враховані наступні характеристики: прохідність місцевості, нові розвіддані про розташування противника на маршруті руху та його можливості по виявленню (веденню розвідки) тактичного підрозділу СВ на маршруті руху, довжина маршруту руху і деякі інші фактори.

Вочевидь, що у загальному випадку основною частиною моделі фукціонуванняя типового бойового об'єкта $є$ підмодель управління цим об'єктом, яка повинна забезпечити не тільки прийняття рішень щодо дій тактичного підрозділу у залежності від характеристик здійснення

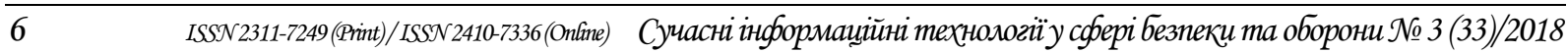


маневру, ведення розвідки та вогневого ураження цілі, але й надати пояснення, чому в умовах поточної оперативно-тактичної обстановки було вибрано саме таке рішення, і показати, що воно $\epsilon$ найбільш ефективним (що реалізується) 3 усіх можливих.

Таким чином, необхідно закласти у модель типового бойового об'єкта інтелектуальні можливості, що дозволить на основі наявної інформації (знаннях про умови оперативнотактичної обстановки, станах та параметрах підмоделей) прийняти рішення про подальші дії бойового об'єкта.

При побудові систем моделювання, які основані на знаннях, найбільш часто використовуються знання отримані від експертів та представлені у вигляді конкретних правил вирішення тих чи інших окремих завдань. Тому пропонується розробити інтелектуальну інформаційну експертну систему продукційного типу [4], яка дозволяє на основі знань висококваліфікованих експертів виробити рекомендації щодо дій тактичного підрозділу в умовах конкретної оперативно-тактичної обстановки.

Для багатьох явищ, які пов'язані управлінням динамічними процесами, необхідна побудова моделі такого процесу. Ця модель дозволяє підібрати відповідний регулятор (модуль управління). Однак, з точки зору 2-го принципу, побудова коректної моделі являє собою важке завдання, яке вимагає введення різних спрощень. Застосування теорії нечітких множин для управління процесами та об'єктами не вимагає детального знання моделей цих процесів і об'єктів. Слід тільки сформулювати правила поведінки об'єктів в процесі їх функціонування у формі нечітких умовних суджень типу IF ... THEN. Класичний модуль нечіткого управління (малюнок 2) складається 3 наступних компонентів: бази правил, блоку фазифікації (перехід до нечіткості), блоку вироблення рішення, блоку дефаззифікації (усунення нечіткості) [4].

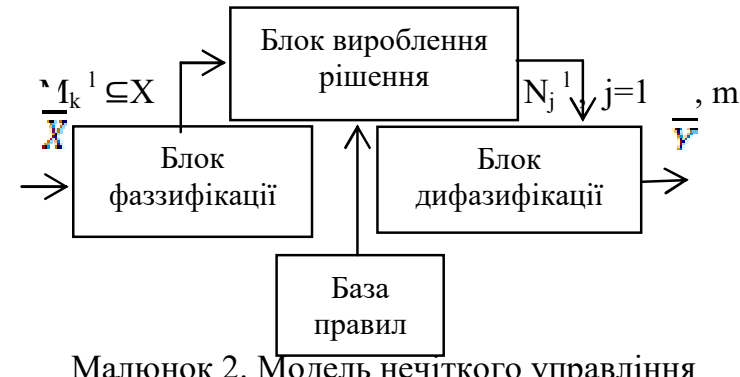

База правил, іноді звана лінгвістичною моделлю, являє собою безліч нечітких правил $\mathrm{P}^{(1)}, 1$ $=1, \ldots, \mathrm{k}$ вида:

$\mathrm{P}^{(1)}:$ IF $\left(\mathrm{x}_{1}\right.$ это $M_{1}^{l}$ AND х ${ }_{2}$ это $M_{2}^{l} \ldots$ AND х

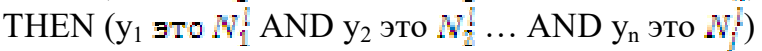

де $\mathrm{K}$ - кількість нечітких правил, які характеризують поведінку підрозділу, що моделюється, у конкретних умовах обстановки;
$M_{h^{-}}^{l}$ - нечіткі множини $M_{R}^{l} \subseteq \mathrm{X}_{\mathrm{k}} \subset \mathrm{P}, \mathrm{k}=1, \ldots, \mathrm{n}, N_{j}^{l}$ -

нечіткі множини $\mathbb{N}_{\mathrm{j}} \subseteq \mathrm{Y}_{\mathrm{j}} \subset \mathrm{P}, \mathrm{j}=1, \ldots, \mathrm{m}, \mathrm{x}_{1}, \mathrm{x}_{2}, \ldots$,

$\mathrm{x}_{\mathrm{k}}$ - вхідні змінні лінгвістичної моделі, причому,

$\left(\mathrm{x}_{1}, \mathrm{x}_{2}, \ldots, \mathrm{x}_{\mathrm{k}}\right)^{\mathrm{s}}=\mathrm{x} \in \mathrm{X}_{1} \mathrm{x} \mathrm{X}_{2} \mathrm{x} \ldots \mathrm{x} \mathrm{X}_{\mathrm{k}}, \mathrm{y}_{1,} \mathrm{y}_{2}, \ldots, \mathrm{y}_{\mathrm{n}}-$

вихідні змінні лінгвістіческоцй моделі, причому

$\left(\mathrm{y}_{1}, \mathrm{y}_{2}, \ldots, \mathrm{y}_{\mathrm{n}}\right)^{\mathrm{s}}=\mathrm{y} \in \mathrm{Y}_{1} \times \mathrm{Y}_{2} \times \ldots \times \mathrm{Y}_{\mathrm{n}}$

Розглянемо процес прийняття рішень для імітаційної моделі бойового об'єкта. Припустимо, на деякому етапі моделювання необхідно прийняти рішення про вибір дій об'єкта. Зауважимо, що, як правило, вибір здійснюється на підставі критеріальних показників, які характеризують дії об'єкта. Однак у разі використання цифрової карти місцевості виникає питання про облік ряду факторів, котрі впливають на ведення бойових дій об'єктом. Тому дії об'єктів будуть характеризуватися параметрами, які відповідають структурі об'єкту, що моделюється [4].

Ці параметри подаються на вхід модуля нечіткого управління. Зіставлення та аналіз значень цих сигналів має дозволити системі управління бойовим об'єктом вибрати відповідні дії в умовах оперативно-тактичної обстановки, яка складається на поточний момент, керуючись рекомендаціями експертів.

На основі заданих експертами функцій приналежності числовим значенням параметрів ставляться у відповідність нечіткі множини $\mathrm{M}^{\mathrm{L}}$.

Визначається ступінь приналежності числового значення параметра до отриманих нечітких множин. Ці ступені будуть визначатися значеннями функцій належності відповідних нечітких множин для кожного параметра. Зіставляються числові значення параметрів по областям, в яких вони мають максимальні ступені приналежності.

На підставі правил, що визначені експертами та отримані на попередньому кроці зіставлень, приймається рішення про вибір варіанта дій об'єкта, що аналізується, у вигляді деякої лінгвістичної змінної або ж видається запит користувачеві про подальші дії об'єкта.

Висновки й перспективи подальших досліджень

Запропонований підхід до аналізу даних Modern Information Technologies in the Sphere of Security and Defence № 3(33)/2018 $\quad$ ISSN2311-7249(Print)/ISSN2410-7336(OnIne) $\quad 7$ 
оперативно-тактичної обстановки, що складається на поточний момент часу, порядку обробки цих даних у засобах імітаційного моделювання бойових дій, що забезпечує облік основних

\section{Лimepamypa}

1. Бобильов В. Є., Зінченко Ю. М., Кононенко С. М. Принципи моделювання. К., НУОУ, 2015 р. 2. Бусленко Н. П. Моделирование сложных систем. Москва, 1961. 3. Andreas Tolk . Engineering Principles of Combat Modeling and Distributed Simulation.; A John Wiley \& Sons Inc., Publication, 2012., 909 p. 4. Рутковская, Д. Нейронные факторів, які впливають на хід та результат бою, що, у підсумку, дозволить підвищити адекватність моделі дій бойового об'єкта в умовах оперативнотактичної обстановки, що постійно змінюється.

\title{
ПОДХОД К АНАЛИЗУ ДАННЫХ В СРЕДСТВАХ ИМИТАЦИОННОГО МОДЕЛИРОВАНИЯ БОЕВЫХ ДЕЙСТВИЙ ВОЙСК (СИЛ)
}

\author{
Виктор Свгеньевич Бобылёв (кандидат воен. наук, с.н.с) \\ Роман Родионович Тимошенко (кандидат техн. наук)
}

\author{
Национальный университет обороны Украины имени Ивана Черняховского, Киев, Украина
}

\begin{abstract}
В статье рассматривается один из возможных методических подходов к построению средств имитационного моделирования боевых действий тактического уровня для тактических подразделений сухопутных войск. Вводится понятие типового объекта для ведения боя, боевой единиць, которая не подлежит делению на более мелкие составляющие и способна самостоятельно выполнять в ходе ведения боевых действий следующие задачи: совершение маневра; ведение разведки противника; ведение огня по противнику, а также принимать решения на выполнение указанных выше задач. Подобные средства имитационного моделирования могут лечь в основу средств имитационного моделирования более высоких уровней управления, в которых основное внимание уделяется проиессу принятия решения. Выполнена формализачия этого прочесса. Предложен подход к анализу и обработке данных, на основе которых принимаются решения по управлению типовым боевым объектом (подразделением).

Ключевые слова: имитационное моделирование, модель управления, принятие решений с помощью средств имитационного моделирования.
\end{abstract}

\section{APPROACH TO THE ANALYSIS OF DATA IN THE SIMULATION TOOLS OF COMBAT ACTIONS OF TROOPS (FORCES)}

\author{
Viktor Y. Bobylov (Candidate of Military Sciences, Senior Research Fellow) \\ Roman R. Timoshenko(Candidate of Technical Sciences)
}

\section{National Defence University of Ukraine named after Ivan Cherniakhovsky, Kyiv, Ukraine}

The following article reveals one of the possible methodologies to design modeling and simulation tools for combat actions at the tactical level with the army tactical units being employed. It introduces the new concept of a representative unit in combat actions. To be more specific, it is a combat unit that cannot be split into smaller constituents and is capable of performing the following tasks independently, such as: maneuvering; intelligence; delivering fire and decision-making. The abovementioned simulation mean promote further command and control simulation tools at high levels, focusing mainly on decision-making process. There has been a formal decision-making framework being developed. One clear approach to analyses and data processing has been worked out for decision-making procedures to command and control a representative combat unit.

Key words: simulation, command and control modeling, decision-making using simulation tools.

\section{References}

1. Bobylov V. Y, Zinchenko Y. M., Kononenko S.M. The Principles of Modeling. K., NDUU, 2015 p. 2. Buslenko N. P. Modeling of complex systems. Moscow, 1961. 3. Andreas Tolk. Engineering Principles of Combat Modeling and Distributed Simulation .; A John Wiley \& Sons Inc., Publication, 2012., 909 p. 4. Rutkovskaya, D. Neural networks, genetic algorithms and fuzzy systems / D. Rutkovskaya, M. Pilinsky, L. Rutkovskaya. M ., Hotline Telecom. 2006. 383 p. 5. Shannon R. Systems Simulation: art and science. M., "Peace” Inc., 1978, 418 p 